\title{
Energy Efficiency of Washing Machines
}

\author{
Nicolae Badea ${ }^{1}$ and Andreia Podasca ${ }^{2}$ \\ 1 “Dunarea de Jos" University of Galati, Domneasca street, no.47 Galati city, Romania \\ 2. Andreia Podasca-BGV Energy Consultancy, P Aristide street 49-51, Bucharest city, Romania
}

\begin{abstract}
This paper makes a technical analysis of the methods to increase the energy efficiency of washing machines for student education. Starting from the definition given by the Energy Efficiency Index, the present analysis proposes two methods for increasing the energy efficiency of the washing machines by modifying the standard annual energy consumption (SAEc) and by modifying the annual energy consumption (AEc). These two methods are made per kilogram of clothes for washing machines from the same brand in different energy classes and for washing machines of two different brands. The models analyzed were chosen according to their energy rating $\mathrm{A}++$ and $\mathrm{A}+++$. The results of this analysis propose the energy savings as an energy indicator to inform buyers in choosing a brand and energy class of the washing machine.
\end{abstract}

Key words: Energy efficiency, appliances, standard testing.

\section{Introduction}

Energy efficiency is one of the means of the European Union to reduce the primary energy use. The 2020 policy aims at a $20 \%$ improvement in energy efficiency at all stages of the energy chain, from generation to final consumption and new policy [1] has been set up to improve the energy efficiency to a further $30 \%$ by 2030 . Among the policies aimed at improving the energy efficiency in Europe, at final consumer level there are energy efficiency standards for eco-design and labelling for a variety of products such as boilers, household appliances, lighting and televisions and washing machines. The residential appliances and equipment represent one of the fastest-growing energy loads. Thus, the energy labels allow consumers to track and check the energy efficiency of products purchased. The labelling schemes for household appliances are cost-effective measures to overcome barriers related to information of buyers about costs of use of household appliances. Evaluation studies [2, 3] based on aggregate observed data find that the existing energy labelling programs for household appliances are effective in terms of

Corresponding author: Nicolae Badea, professor, Ph.D., research field: energy. energy and carbon reductions. Some studies on washing machines in particular show that the consumers "stated choices for washing machines observe that eco-labelling affects consumers" [4] purchasing decisions.

\section{Legal Framework for Energy Efficient Products}

In order for the European Union to move the market towards more energy efficient products, it has implemented two framework regulations:

- The Ecodesign Regulation [5] requires manufacturers to decrease the energy consumption of their products by establishing minimum energy efficiency standards;

- The Energy Labelling Regulation [6] is a tool through which consumers can recognize the best performing products. The section headings are in boldface capital and lowercase letters. Second level headings are typed as part of the succeeding paragraph.

The products covered are labeled in the following way:

- Energy-using products (EuPs): products that use energy to fulfill their function (TV, washing machines, etc.) as well as industrial products that transfer, use 
and generate energy;

- Other energy related products (ErPs): products that do not use energy to fulfil their function but have a significant impact on the energy consumption and can therefore contribute to saving energy (such as windows, insulation materials, etc.).

Mandatory energy performance requirements and labels promoted by the EU [7, 8] have proved to be a highly cost-effective policy tool encouraging the reduction of average energy consumption of the residential appliances and equipment and are estimated to produce [8] an energy saving of around 175 Mtoe (million tons of oil equivalent) by 2020 . Most products are labelled [9] on a scale of $\mathrm{A}+++$ (most efficient) to $\mathrm{G}$ (least efficient).

\section{The Energy Efficiency Classes of a Household Washing Machine}

From an energy point of view, the residential washing machines are characterized by three given indicators [7]: the standard $60{ }^{\circ} \mathrm{C}$ cotton program at full and partial load and the standard $40{ }^{\circ} \mathrm{C}$ cotton program at partial load:

- Energy efficiency classes of residential washing are determined on the basis of its energy efficiency index (EEI). According to Annex VI [10] of the EEI, energy efficiency classes are covered from the $\mathrm{A}+++$ class as the most efficient with an EEI $<46$ to the D class as the least efficient with an EEI $>87$. For the calculation of the EEI of a household washing machine model, the weighted annual energy consumption of a household washing machine for the standard $60{ }^{\circ} \mathrm{C}$ cotton program at full and partial load and for the standard $40{ }^{\circ} \mathrm{C}$ cotton program at partial load, based on 220 standard wash cycles per year, equivalent to 4.2 washing cycles per week, is compared to its standard annual energy consumption. The EEI is rounded to one decimal place and is calculated, according to Annex VII of the EEI, as follows:

$$
E E I=\frac{A E c}{S A E c} \times 100
$$

where:

$S A E c$ is standard annual energy consumption of the household washing machine calculated in $\mathrm{kWh} /$ year and is rounded to one decimal place:

$$
S A E c=47,0 \times c+51,7
$$

$c$ is rated capacity of the household washing machine for the standard $60^{\circ} \mathrm{C}$ cotton program at full load or the standard $40{ }^{\circ} \mathrm{C}$ cotton program at full load, whichever is the lower.

$A E c$ is the annual energy consumption of the household washing machine and is calculated in $\mathrm{kWh} / \mathrm{year}$ and is rounded to two decimal places:

$$
A E c=E_{t} \times 220+\frac{P_{o} \times \frac{525600-\left(T_{t} \times 200\right)}{2}+P_{l} \times \frac{525600-\left(T_{t} \times 200\right)}{2}}{60 \times 1000}
$$

$E_{t}=$ weighted energy consumption is calculated in $\mathrm{kWh}$ and is rounded to three decimal places:

$$
E_{t}=\frac{3 \times E_{t, 60}+2 \times E_{t, 601 / 2}+2 \times E_{t, 401 / 2}}{7} ;
$$

$E_{t, 60}=$ energy consumption of the standard $60{ }^{\circ} \mathrm{C}$ cotton program at full load;

$E_{t, 601 / 2}=$ energy consumption of the standard $60{ }^{\circ} \mathrm{C}$ cotton program at partial load;

$E_{t, 40 \frac{1}{2}}=$ energy consumption of the standard $40{ }^{\circ} \mathrm{C}$ cotton program at partial load.
$P_{o}=$ weighted power in "off-mode";

$P_{l}=$ weighted power in the "left-on mode";

$T_{t}=$ weighted program time is calculated in minutes and is rounded to the nearest minute:

$$
T_{t}=\frac{3 \times T_{t, 60}+2 \times T_{t, 601 / 2}+2 \times T_{t, 401 / 2}}{7}
$$

$T_{t, 60}, T_{t, 601 / 2} T_{t, 401 / 2}$ is the program time of the standard condition previously exposed;

$220=$ total number of standard washing cycles per year. 
- The weighted annual water consumption (AWc) of a household washing machine is calculated in liters multiplying the weighted water consumption with the total number of standard washing cycles per year:

$$
\mathrm{AWc}=\mathrm{W}_{\mathrm{t}} \times 220
$$

where:

$W_{t}=$ weighted water consumption is calculated in liters and is rounded up to the integer:

$$
W t=\frac{3 \times W_{t, 60}+2 \times W_{t, 601 / 2}+2 \times W_{t, 401 / 2}}{7} ;
$$

$W_{t, 60}, W_{t, 60^{1 / 2}} W_{t, 40^{1 / 2}}$ is the water consumption of the standard condition previously exposed.

- Spin-drying efficiency classes of a household washing machine are determined on the basis of the remaining moisture content $(D)$. From this point view spin-drying efficiency classes are from $\mathrm{A}+++$ class as the most efficient with $\mathrm{D}<45$ to the $\mathrm{G}$ class as the least efficient with $\mathrm{D}>90$. This is dependent on the maximum spin speed of the washing machine. The weighted remaining moisture content (D) of a household washing machine is calculated in percentage as follows and rounded to the nearest whole percent:

$$
\mathrm{D}=\left(3 \times \mathrm{D}_{60}+2 \times \mathrm{D}_{601 / 2}+2 \times \mathrm{D}_{401 / 2}\right) / 7
$$

where:

$\mathrm{D}_{60}$ is the residual moisture content for the standard $60{ }^{\circ} \mathrm{C}$ cotton program at full load, in percentage and rounded to the nearest whole per cent;

$\mathrm{D}_{601 / 2}$ is the residual moisture content for the standard $60{ }^{\circ} \mathrm{C}$ cotton program at partial load, in percentage and rounded to the nearest whole per cent;

$\mathrm{D}_{40 \frac{1}{2}}$ is the residual moisture content for the standard $40{ }^{\circ} \mathrm{C}$ cotton program at partial load, in percentage and rounded to the nearest whole per cent.

\section{Methodology}

Starting from the definition given by the EEI, the present analysis proposes two methods for increasing the energy efficiency of the washing machines by modifying the standard annual energy consumption
(SAEc) and by modifying the annual energy consumption (AEc). The analysis of the two methods is made per kilogram of clothes for washing machines from the same brand in different energy classes and for washing machines of two different brands. The models analyzed were chosen according to their energy rating $\mathrm{A}++$ and $\mathrm{A}+++$. The results of this analysis propose the energy savings as an energy indicator to inform buyers in choosing a brand and energy class of the washing machine.

\section{Case Study for Increasing the Energy Efficiency of the Washing Machine}

Increasing the energy efficiency of the washing machine determined on the basis of its EEI theoretically implies either increasing the standard annual energy consumption by rated capacity increasing or reducing the annual energy consumption. In order to compare the methods for action that allow the reduction of the EEI from the $\mathrm{A}++$ class to the A+++ class, Table 1 presents the specific characteristics given by the user manual for two brands, Arctic and Samsung, for washing machines with a capacity of $7 \mathrm{~kg}$ and $8 \mathrm{~kg}$ respectively. Based on this information the weighted energy consumption, weighted program time, standard annual energy consumption, annual energy consumption and EEI have been determined for each type of washing machine. On the basis of absolute values from Table 1 it can be identified at the Arctic brand a reduction of 2 $\mathrm{kWh} /$ year from $\mathrm{A}+++$ class to $\mathrm{A}++$ class compared to Samsung brand where the reduction of consumption is $28 \mathrm{kWh} /$ year. Within the same energy class, Samsung has consumption larger with $7 \mathrm{kWh} / \mathrm{yr}$ at $\mathrm{A}++$ class but is smaller with $19 \mathrm{kWh} / \mathrm{yr}$ at $\mathrm{A}+++$ class.

\section{Methods for Analysis}

Comparing washing machines in different classes and brands with the absolute values given in Table 1, the methods for increasing the energy efficiency applied by the two brands cannot be identified. But 
Table 1 Washing machine characteristics.

\begin{tabular}{|c|c|c|c|c|}
\hline \multirow{2}{*}{$\begin{array}{l}\text { Brand } \\
\text { Energy rating }\end{array}$} & \multicolumn{2}{|c|}{ Artic $^{*}$} & \multicolumn{2}{|c|}{ Samsung** } \\
\hline & $\mathrm{A}++$ & $\mathrm{A}+++$ & $\mathrm{A}++$ & $\mathrm{A}+++$ \\
\hline Annual energy consumption AEc $[\mathrm{kWh} / \mathrm{yr}]$ & 194.478 & 192.419 & 201.832 & 173.581 \\
\hline Weighted energy consumption $\mathrm{E}_{\mathrm{t}}[\mathrm{kWh}]$ & 0.862 & 0.852 & 0.817 & 0.689 \\
\hline Energy consumption $\left(\mathrm{E}_{\mathrm{t}, 60}\right)$ at full load $[\mathrm{kWh}]$ & 1.001 & 1.069 & 0.98 & 0.88 \\
\hline Energy consumption $\left(\mathrm{E}_{\mathrm{t}, 601 / 2}\right)$ at partial load $[\mathrm{kWh}]$ & 0.767 & 0.7 & 0.79 & 0.68 \\
\hline Energy consumption $\left(\mathrm{E}_{\mathrm{t}, 401 / 2}\right)$ at partial load [kWh] & 0.747 & 0.68 & 0.6 & 0.41 \\
\hline Weighted program time $T_{t}[\mathrm{~min}]$ & 162 & 186 & 213 & 209 \\
\hline$T_{t, 60}$ Cotton $60^{\circ} \mathrm{C}$ at full load $[\mathrm{min}]$ & 176 & 200 & 240 & 242 \\
\hline$T_{t, 601 / 2}$ Cotton $60^{\circ} \mathrm{C}$ at partial load [min] & 151 & 175 & 212 & 194 \\
\hline$T_{t, 401 / 2}$ Cotton $40^{\circ} \mathrm{C}$ at partial load [min] & 151 & 175 & 172 & 174 \\
\hline$P_{o}$ weighted power in "off-mode" $[\mathrm{W}]$ & 0.25 & 0.2 & 0.48 & 0.48 \\
\hline $\mathrm{P}_{1}=$ weighted power in the "left-on mode" $[\mathrm{W}]$ & 1 & 1 & 5 & 5 \\
\hline Standard annual energy consumption $[\mathrm{kWh} / \mathrm{yr}]$ & 380.7 & 427.7 & 380.7 & 427.7 \\
\hline Capacity $[\mathrm{kg}]$ & 7 & 8 & 7 & 8 \\
\hline Energy Efficiency Index (EEI) & 51 & 45 & 53 & 41 \\
\hline Weighted annual water consumption [L/yr] & 9,460 & 11,000 & 9,400 & 10,500 \\
\hline Maximum spin speed & 1,200 & 1,200 & 1,400 & 1,400 \\
\hline Residual moisture D [\%] & 53 & 53 & 53 & 53 \\
\hline Spin-drying efficiency classes & B & B & B & B \\
\hline
\end{tabular}

* type AFD7200A++ and AFD8200A+++ [11]; ** type WF70F5E*N4* A++ and WF80F5E*U4A+++ [12].

reporting the data in Table 1 to the capacity of the washing machine, a reference can be made that can enable a comparison between washing machines from the same energy class but from different brands and in different energy classes from the same brand.

The relevant data are specific energy consumption per cycle and time duration from the AEc relation, respectively specific water consumption per cycles and specific energy consumption AEc and standard energy consumption SAEc from EEI formula.

The data presented in Table 2 help identify the following methods for increasing the energy efficiency of washing machines:

- Modifying the SAEc through capacity increase allows the analysis of the technological changes for each brand:

$\circ$ Artic reduced the specific weighted energy consumption in $\mathrm{A}+++$ class with $13 \%$ keeping the weighted program time constant compared to $\mathrm{A}++$ class;

o Samsung reduced the specific weighted energy consumption in $\mathrm{A}+++$ class with $26 \%$ and reduced the weighted program with $13 \%$ compared to $\mathrm{A}++$ class.

$\circ$ Defining the energy efficiency of the washing machine with the relation: Efficiency $=\left(1-\frac{A E c}{S A E c}\right) \cdot 100$.

○ "energy efficiency improvement" means an increase in energy efficiency as a result of technological changes. For Artic the increase is of $6 \%$ whole Samsung obtained an improvement of $11 \%$. The motivation for the improvement is the reduced weighted annual energy consumption in left-on mode and off-mode per cycle compared to weighted energy consumption.

- The AEc changes by constantly maintaining the capacity indicate that technological changes of the brands lead to the reduction of the weighted energy consumption. Different energy efficiency improvements between brands as a result of technological changes lead to an increase of $2 \%$ in the $\mathrm{A}++$ class to $4 \%$ in the $\mathrm{A}+++$ class. The heating up of 
Table 2 Comparative data per capacity.

\begin{tabular}{|c|c|c|c|c|}
\hline \multirow{2}{*}{$\frac{\text { Brand }}{\text { Energy rating }}$} & \multicolumn{2}{|c|}{ Artic $^{*}$} & \multicolumn{2}{|c|}{ Samsung** } \\
\hline & $\mathrm{A}++$ & $\mathrm{A}+++$ & $\mathrm{A}++$ & $\mathrm{A}+++$ \\
\hline Annual energy consumption AEc $[\mathrm{kWh} / \mathrm{kgyr}]$ & 28 & 24 & 29 & 22 \\
\hline Weighted energy consumption $E_{t}[\mathrm{Wh} / \mathrm{kg}]$ & 123 & 107 & 117 & 86 \\
\hline Weighted program time $T_{t}[\mathrm{~min} / \mathrm{kg}]$ & 23 & 23 & 30 & 26 \\
\hline Annual energy consumption in left-on mode and off-mode' per cycle [Wh/kgyr] & 3 & 3 & 14 & 13 \\
\hline Standard annual energy consumption $[\mathrm{kWh} / \mathrm{kgyr}]$ & 54 & 53 & 54 & 53 \\
\hline Capacity $[\mathrm{kg} / \mathrm{kg}]$ & 1 & 1 & 1 & 1 \\
\hline Water consumption per cycles $[\mathrm{L} / \mathrm{kg}]$ & 5 & 6 & 6 & 6 \\
\hline Efficiency $[\%]$ & 49 & 55 & 47 & 59 \\
\hline
\end{tabular}

the water is the most energy consuming process in a wash cycle and result is that the washing energy consumption is mostly affected by wash temperature. The correlation between the water heating time constant and the heating intensity is essential in reducing the washing energy consumption.

\section{Conclusions}

The analysis of the methods for increasing the energy efficiency of the washing machines can be achieved through the modification of the capacity and/or change of the annual energy consumption. The energy savings are between 2 and $28 \mathrm{kWh} / \mathrm{yr} \mathrm{kg}$ and show the difference between the two brands. Energy efficiency improvement as a result of technological changes is measured by energy savings and means an amount of saved energy determined by estimating consumption before and after implementation of an energy efficiency improvement measure. These energy savings must be highlighted on the energy label of washing machines to inform buyers of the benefits of the superior classes of washing machines of each brand. The information of the buyer to evaluate energy efficiency opportunities on energy consumption and the energy performance of technologies is expected to affect the adoption of energy-efficient technologies.

\section{References}

[1] Proposal for a Directive of the European Parliament and of the Council Amending Directive 2012/27/EU on
Energy Efficiency COM/2016/0761 final, 2016/0376 (COD).

[2] Sanchez, M. C., Brown, R. E., Webber, C., and Homan, G. K. 2008. "Savings Estimates for the United States Environmental Protection Agency's ENERGY STAR Voluntary Product Labeling Program.” Energy Policy 36: 2098-108.

[3] Linden, A-L., Carlsson-Kanyama, A., and Eriksson, B. 2006. "Efficient and Inefficient Aspects of Residential Energy Behaviour: What Are the Policy Instruments for Change?" Energy Policy 34: 1918-27.

[4] Sammer, K., and Wüstenhagen, R. 2006. "The Influence of Eco-Labelling on Consumer Behaviour-Results of a Discrete Choice Analysis for Washing Machines." Business Strategy and the Environment 15: 185-99.

[5] The Ecodesign Directive 2009/125/EC of the European Parliament and of the Council of 21 October 2009 Establishing a Framework for the Setting of Ecodesign Requirements for Energy-Related Products.

[6] The Energy Labelling Directive 2010/30/EU of the European Parliament and of the Council of 19 May 2010 on the Indication by Labelling and Standard Product Information of the Consumption Of Energy and Other Resources by Energy-Related Products.

[7] http://ec.europa.eu/enterprise/policies/sustainable-busines $\mathrm{s} /$ documents/ecodesign/legislation/framework-directive/i ndex_en.htm\#h2-1.

[8] http://www.eceee.org/ecodesign/.

[9] http://ec.europa.eu/energy/en/topics/energy-efficiency/en ergy-efficient-products.

[10] Commission Delegated Regulation (EU) No. 1061/2010 of 28 September 2010 supplementing Directive 2010/30/EU of the European Parliament and of the Council with regard to Energy Labelling of Household Washing Machines.

[11] https://www.arctic.ro/media/products/manuale/AFD8200 A+++.pdf.

[12] F400E_NonBubble_WF70F5E_03445H-02. 